\title{
Feeling in control: comparing older people's experiences in different care settings
}

\author{
LISA CALLAGHAN* and ANN-MARIE TOWERS*
}

\begin{abstract}
The promotion of choice and control for older people is a policy priority for social care services in the United Kingdom and is at the heart of recent drives to personalise services. Increasingly, we are seeing a move away from institutionalised care (e.g. in care homes) towards enablement, with more services being delivered in communitybased settings. Extra care housing has been promoted as a purpose-built, communitybased alternative to residential care for older people. However, whilst accounts of users' experiences in particular service types are plentiful, the use of different instrumentation and measures makes comparison between settings difficult. We combined data from four studies where participants were older people either living in care homes or extra care housing or receiving care at home. All of these studies asked participants to rate their control over daily life, using the Adult Social Care Outcomes Toolkit (ASCOT). This paper presents the results of an ordinal logistic regression analysis indicating that, after controlling for differences in age, ability to perform activities of daily living and self-rated health, setting had a significant effect on older people's sense of control. Residents in care homes and extra care housing report similar levels of control over daily life but consistently report feeling more in control than older people receiving care at home. Implications for policy and practice are discussed.
\end{abstract}

KEY WORDS-control, older people, care homes, extra care housing, home care, Adult Social Care Outcomes Toolkit (ASCOT).

\section{Introduction}

The promotion of choice and control for older people is a policy priority for both health and social care services in the United Kingdom (UK) and is at the heart of recent drives to personalise services and move service users and carers on to personal budgets (PBs) (Department of Health 2010; HM Government 2010). Research has indicated that personalisation in the form

* Personal Social Services Research Unit, University of Kent, Canterbury, UK. 


\section{Lisa Callaghan and Ann-Marie Towers}

of PBs can deliver positive outcomes, including increased control, for services users (Glendinning et al. 2008; Hatton and Waters 2011 ). However, there is also evidence that older people may not in fact experience increased control over their lives when using PBs (Hatton and Waters 2011; Netten et al. $2012 b$; Slay 2011 ). Various suggestions have been put forward in attempting to explain this: it may be that the process of planning and managing a PB results in greater anxiety for older people than younger people (Netten et al. 2012b); PBs for older people are often much lower than for other groups (Slay 2011); and older people may be less likely to use PBs in ways found to be associated with positive outcomes, such as taking the $\mathrm{PB}$ as a direct payment, and are more likely to have their PB managed by the council, therefore not truly gaining control (Hatton and Waters $2011)$.

In addition, a recent inquiry into older people and human rights in home care by the Equality and Human Rights Commission (EHRC) raised concerns about the effectiveness of PBs and direct payments for offering older people more choice and control (EHRC 2011). The EHRC found evidence of $\mathrm{PBs}$ being delivered poorly, with some older people finding the responsibilities of PBs daunting and disempowering and others 'being moved onto budgets managed by the local authority without gaining any choice and control over care provision' (2011:65).

For older people receiving care, it seems that having control is less to do with managing by oneself and more to do with having control over the delegation of their care and responsibilities (Bamford and Bruce 2000; Qureshi et al. 1998) and influencing how and when care and support is delivered (Gabriel and Bowling 2004; Qureshi and Henwood 2000; Qureshi et al. 1998). What older people describe as being important to them is having control over their daily lives (Hayden, Boaz and Taylor 1999; Raynes 1998; Tester et al. 2004) with personalised, responsive services, regardless of how their funding is arranged (EHRC 2011). However, an increasing challenge for policy makers and practitioners is how best to provide this when faced with a growing population of older people with diverse needs and wishes.

Increasingly, we have seen a move away from institutionalised care (e.g. in care homes) towards 'enablement', with more services being delivered in community-based settings (Department of Health 2010; Windle et al. 2009). Indeed, key to the policies of previous and current UK governments has been the aim to help people maintain their independence in their own homes for as long as possible, receiving domiciliary care and adaptations to their home as needed (Department for Communities and Local Government 2008; Department of Health 2010; Office of the Deputy Prime Minister 2006). Ageing in place can be problematic, however, not 
least because much of Britain's housing stock is unsuitable for adaptation (Darton and Muncer 2005). Restricted to living in only one or two rooms, many older people report being prisoners in their own homes, socially isolated and at risk from depression and anxiety (Baker 2002; Bartholomeou 1999; Oldman 2000; Riseborough and Niner 1994). In some instances, systemic failings in the delivery of domiciliary care have led to some older people's basic human rights being failed (EHRC 2011). Accounts of the negative aspects of 'staying put' (Aronson 2002; Barrett, Hale and Gauld 2012; EHRC 2011) have led some to question the 'rightness' of striving to maintain independence when living alone with increasing frailty (Aronson 2002; Boyle 2004; Dalley 2002).

Housing with care, such as extra care housing (ECH) or continuing care retirement communities, has been promoted as a purpose-built, communitybased alternative to moving into residential care for older people (e.g. Department of Health 2005). It aims to meet the housing, care and support needs of older people, while helping them to maintain independence in private accommodation (Department of Health 2008), and is seen as a positive option for older people in current social care policy (Department of Health 2010). Key features of ECH are that it is primarily for older people; accommodation is self-contained; care is delivered flexibly by staff often based onsite; staff are available 24 hours a day; domestic care is available; meals are usually available; and it offers security of tenure (Laing and Buisson 2010). The expectation is that $\mathrm{ECH}$ will afford older people a greater sense of control over their lives than more institutional settings, such as care homes, whilst avoiding the pitfalls of 'staying put', such as disjointed care, social isolation and inappropriate housing.

There have been several studies in which older people living in ECH have been asked about their experiences and have reported high levels of satisfaction (see Croucher, Hicks and Jackson 2006). Feeling that they have retained more control over their lives than they would have in residential care is frequently mentioned as being valued. However, the evidence has largely come from evaluations of new and innovative housing with care schemes, which market themselves as promoting independence and providing positive alternatives to institutional models of care (Croucher, Hicks and Jackson 2006). In fact, a recent study of the expectations and experiences of older people moving into residential care (Darton 2011) suggests that the expectation that residential care is associated with a total loss of control and independence can be overly pessimistic. Most of the 69 residents, interviewed after settling into a care home, told researchers they had more control over their lives than they had expected before moving in and the percentage rating their quality of life as good or very good rose by 12 per cent (Darton 2011). Furthermore, Boyle (2004) found that older 


\section{$143^{\circ}$ Lisa Callaghan and Ann-Marie Towers}

people in residential care experienced the most control and people receiving domiciliary care the least, when she conducted semi-structured interviews with older people living in care homes (residential and nursing) or in the community.

Surprisingly, studies such as Boyle's (2004) are difficult to find in the UK literature. There has been seemingly little research directly comparing older people's sense of control in different care settings, despite the policy agenda. Most research has tended to look more broadly at older people's experiences in a single setting: care homes (Bowers et al. 2009; Darton 2011 ; Kane et al. 2004; Raynes 1998; Taylor et al. 2009; Train et al. 2005); ECH (Bäumker et al. 2012; Callaghan, Netten and Darton 2009; see also Croucher, Hicks and Jackson 2006 for a review) or home care (Aronson 2002; Barrett, Hale and Gauld 201 2; EHRC 201 1; Raynes et al. 2001). Where comparisons have been made, they have tended to focus on broader quality of life issues or physical and cognitive functioning, and have focused on comparing two main care options, such as extra care to domiciliary care (Bernard et al. 2007; Gardner, Browning and Kendig 2005; Kingston et al. 2001; Kneale 2011 ), extra care to residential care (Darton et al. $2011 a$ ) or domiciliary care to residential care (Boyle 2004).

Thus, important questions remain about the relative benefits of different settings with respect to control over daily life. Comparisons are difficult to make because where studies have asked about 'control', they have done so in different ways using a variety of scales and methods. Studies typically have a broader focus on user satisfaction, wellbeing or quality of life, and although control is frequently mentioned, it has not always been asked about in a way that is easily quantifiable. There is also the issue that people use the term 'control' interchangeably with concepts such as autonomy, independence, locus of control and many more (see Skinner 1996 for a review of relevant terminology). For the purposes of this paper, we are talking specifically about control over daily life, which is desired and valued by service users (Hayden, Boaz and Taylor 1999; Raynes 1998; Tester et al. 2004) and defined here within the framework of social care-related quality of life (SCRQoL) (Netten et al. $2012 a$ ).

\section{Social care-related quality of life}

The Adult Social Care Outcomes Toolkit (ASCOT) (Netten et al. 2012a) has been developed and designed to measure those aspects of quality of life specifically relating to social care and can be applied across different care settings (http://www.pssru.ac.uk/ascot/). A series of studies has investigated and tested the domains of quality of life most relevant to social care in a 


\section{T A в L E 1. Social care-related quality of life (SCRQoL) domains}

\begin{tabular}{|c|c|}
\hline Domains of SCRQoL & Definition \\
\hline $\begin{array}{l}\text { Personal cleanliness and } \\
\text { comfort }\end{array}$ & $\begin{array}{l}\text { The service user feels he/she is personally clean and } \\
\text { comfortable and looks presentable or, at best, is dressed and } \\
\text { groomed in a way that reflects his/her personal preferences. }\end{array}$ \\
\hline Safety & $\begin{array}{l}\text { The service user feels safe and secure. This means being free } \\
\text { from fear of abuse, falling or other physical harm, and fear of } \\
\text { being attacked or robbed. }\end{array}$ \\
\hline Control over daily life & $\begin{array}{l}\text { The service user can choose what to do and when to do it, } \\
\text { having control over his/her daily life and activities. }\end{array}$ \\
\hline $\begin{array}{l}\text { Accommodation cleanliness } \\
\text { and comfort }\end{array}$ & $\begin{array}{l}\text { The service user feels their home environment, including all } \\
\text { the rooms, is clean and comfortable. }\end{array}$ \\
\hline Food and nutrition & $\begin{array}{l}\text { The service user feels he/she has a nutritious, varied and } \\
\text { culturally appropriate diet with enough food and drink that } \\
\text { he/she enjoys at regular and timely intervals. }\end{array}$ \\
\hline Occupation & $\begin{array}{l}\text { The service user is sufficiently occupied in a range of } \\
\text { meaningful activities, whether it be formal employment, } \\
\text { unpaid work, caring for others or leisure activities. }\end{array}$ \\
\hline $\begin{array}{l}\text { Social participation and } \\
\text { involvement }\end{array}$ & $\begin{array}{l}\text { The service user is content with their social situation, where } \\
\text { social situation is taken to mean the sustenance of } \\
\text { meaningful relationships with friends, family and feeling } \\
\text { involved or part of a community, should this be important to } \\
\text { the service user. }\end{array}$ \\
\hline Dignity & $\begin{array}{l}\text { The negative and positive psychological impact of support } \\
\text { and care on the service user's personal sense of significance. }\end{array}$ \\
\hline
\end{tabular}

Source: http://www.pssru.ac.uk/ascot/domains.php.

number of different contexts, including in care homes for older people and people with a learning disability (Netten $e t a l$. 2010, 2012c), day centres for older people (Caiels et al. 2010) and an evaluation of individual budgets (Glendinning et al. 2008). The items have demonstrated good construct validity with older people (Malley et al. 2012). The eight domains of SCRQoL that the ASCOT measure draws on are described in Table 1.

The ASCOT was developed over a number of years and through a variety of studies, meaning that the wording of some of the domains has changed significantly over time and between studies. However, the control over daily life domain has changed relatively little and what differences do exist can be largely resolved through some simple recoding and collapsing of response categories (see Method section for further details). Over the course of four different research studies (Callaghan, Netten and Darton 2009; Netten et al. 2010, 2012a; Towers 2006), we have collected data about older people's control over daily life in different care settings. Thus, the aim of this paper is to examine the association between control over daily life and the setting in which older people receive care and support (be that in ECH, care homes or at home). 


\section{Method}

The research procedures for each project received ethical approval from an appropriate board, and information collected was subject to informed consent.

\section{Study I: 'Social Well-being in Extra Care Housing' project}

Between 2006 and 2010, the Personal Social Services Research Unit (PSSRU) at the University of Kent undertook an evaluation of the first two rounds of the English Department of Health's $£ 87$ million Extra Care Housing Funding Initiative (2004-06), evaluating 19 new-build ECH schemes that received initial support from the fund and which opened between 2006 and 2008 (Darton et al. 2011 b; Netten et al. $2011 a$ ).

Each scheme planned to provide social activities for residents and facilitate community participation. This presented an opportunity to add to the data being collected by investigating the development of the social life of these schemes and exploring the social wellbeing of residents. This aspect of the work was funded by the Joseph Rowntree Foundation (JRF), and research was carried out over three years, between 2006 and 2009 (Callaghan, Netten and Darton 2009). The project involved 15 of the schemes included in the main evaluation. It focused on the first year after each scheme opened, and aimed to identify how schemes had begun to develop community and social activities during their first six months. Following this, differences in individual social wellbeing in schemes one year after opening were identified.

The data used for the analysis described here were collected through a structured questionnaire which included questions about the social life at the scheme, levels of participation and barriers to taking part, contact with friends and family, as well as overall quality of life and self-perceived health (SPH). This questionnaire also included the control over daily life question from the ASCOT. Trained fieldworkers for each scheme were available to offer support in completing this questionnaire, and in fact many residents preferred to take up this option. All residents were invited to take part, and 599 completed questionnaires were received. For the purposes of this paper, we draw on a subset (102) of these questionnaires, only using those from people living in extra care schemes (not villages) and receiving care. The project also made use of information collected as part of the main evaluation about residents' demographic information, health, dependency and service receipt.

\section{Study 2: 'Measuring the Outcomes of Care Homes' project}

This research project was part of the 'Measuring Outcomes for Public Service Users' (MOPSU) project, which was funded over three years (2007-09) by 
the Treasury under the Invest to Save budget and led by the Office for National Statistics. The aim of the project was to develop and test an approach to measuring outcomes of the care and support provided to residents of care homes for older people and people with learning disabilities (Netten et al. 2010).

The project developed and tested a multi-method approach to measuring outcomes to address the challenge of obtaining meaningful data from care home residents who may be very vulnerable and have cognitive impairments or communication difficulties. As part of this multi-method approach, fieldworkers conducted structured observations and interviews with staff. Where residents had capacity to consent and were able to understand the questions and communicate their responses, structured, face-to-face interviews also took place.

The care homes that took part in the study were randomly selected from homes in England that had recently been or were imminently due an inspection by the regulator, which at the time was the Commission for Social Care Inspection. The study aimed to include a representative number of care homes from all quality ratings (poor, adequate, good and excellent), however, we had difficulty recruiting homes rated as 'poor' to the study and these were under-represented in the sample (Netten et al. 2010).

Detailed data were collected by trained fieldworkers for up to five residents per home. Information about the residents' age, ethnicity, physical functioning, and care and nursing needs was collected alongside data on SCRQoL, as measured by the ASCOT. Final ASCOT ratings were based on the evidence collected using the multi-method approach. For those unable to take part in a structured interview, ASCOT scores are based on fieldworker observations and staff ratings. This is not comparable to the other studies reported here, where service user views were collected directly through interviews. Consequently, for the purposes of the present analysis, we have included only those residents that took part in the face-to-face interviews and gave their own ratings control over daily life as measured by the ASCOT. This is directly comparable with the other studies included in this analysis.

\section{Study 3: 'Control and Well-being' project}

This project was conducted as part of the PSSRU's programme of research funded by the English Department of Health (Towers 20o6). The project involved comparing older people's sense of control and psychological wellbeing in care homes and ECH in two local authorities in England. It also collected information about how much control people had over various aspects of their daily routine and examined whether there was an association between this and feeling in control. The research question was whether good 


\section{Lisa Callaghan and Ann-Marie Towers}

quality care homes could afford their residents as much choice and control as housing with care schemes. Consequently, all the care homes that took part in the study were considered to be good homes by the local authority and had met or exceeded the regulator's standards for 'Choice and Control'. Local authorities also considered all of the participating extra care schemes to be providing good quality housing and care.

Trained fieldworkers conducted face-to-face interviews with $18_{3}$ older people living in care homes $(\mathrm{N}=89)$ and very sheltered housing (a precursor to extra care) $(\mathrm{N}=94)$. Information in addition to the ASCOT control over daily life question included: residents' demographic information, health and dependency, questions about control over daily routine and subjective wellbeing. For the purposes of this paper, only the care home sample has been included in the analysis and merged with the care home sample from Study 2 to boost sample sizes.

\section{Study 4: 'Outcomes of Social Care for Adults' project}

The overall aim of this project was to develop the final version of the ASCOT preference-weighted measure of outcome that would reflect the impact on and value of social care to those who use such services (Netten et al. 2012a). The project consisted of two stages. The first phase involved development and feasibility work while during the second phase the preference weights for the final measure were estimated.

As part of the development of the measure, the questions were tested through the annual user experience survey (UES) conducted by local councils. During 2009, ten councils across England took part in the UES of older people (aged over 65) receiving home care services. From the respondents to the UES, a sampling frame was generated from those who indicated that they would be happy to take part in further research. This resulted in a sample of 301 people (a response rate of $53 \%$ ), which is the sample used for the analysis presented in this paper. Data were collected through face-to-face interviews, and interviewers were briefed prior to interviewing. Information in addition to the SCRQoL questions included demographic characteristics, service receipt, quality of life and psychological wellbeing, health, dependency, feelings of control, social contact and support, and participation in groups and volunteering.

\section{Current analysis}

As described above, the aim of the current project was to examine the association between control over daily life and the setting in which older people receive care and support (be that in ECH, care homes or at home). 


\section{T A B L E 2. Wording of control question and level of need}

\begin{tabular}{ll}
\hline Question wording & Level of need \\
\hline Setting: Extra care housing: & \\
Which of the following statements best describes your present situation? & \\
I feel in control of my daily life & No needs \\
The help I get here helps me feel in control of my daily life & No needs \\
I have some control over my daily life but not enough & Some needs \\
I have no control over my daily life & High needs \\
Setting: Care homes: & \\
Which of the following statements best describes how much control you & \\
have over your daily life? & \\
I feel in control of my daily life & No needs \\
With help I feel in control of my daily life & No needs \\
I have some control over my daily life but not enough & Some needs \\
I have no control over my daily life & High needs \\
Setting: Receiving care at home: & \\
Which of the following statements best describes how much control you & \\
have over your daily life? & \\
I have as much control over my daily life as I want & No needs \\
I have adequate control over my daily life & No needs \\
I have some control over my daily life but not enough & Some needs \\
I have no control over my daily life & High needs \\
\hline
\end{tabular}

Measures. Social care-related quality of life: The wording used for the control over daily life question was slightly different across the four projects described above. However, the question measures the same underlying concepts, and in analysis particular categories are used to indicate 'high', 'some' and 'no' needs in each domain. This is in keeping with the latest ASCOT terminology (www.pssru.ac.uk/ASCOT). Table 2 shows the question wording for each category, and the level of need each was designed to indicate. For each variable, scores were recoded to indicate no need, some need or high need.

Dependency and health: The four projects collected a variety of data about participants' demographic characteristics, health and dependency. For the present analysis, we only included measures that were common to them all. For dependency, each project included some of the questions used to make up the Barthel Index of Activities of Daily Living (Mahoney and Barthel 1965 ), a summary measure used to indicate the participant's ability to perform a range of 'activities of daily living' (ADLs), such as getting in and out of bed, moving around inside the home and using the toilet. Each item is scored according to four levels of ability, indicating ability to do the activity 'on your own without difficulty', 'on your own with difficulty', 'only with help' or 'not at all'. If all items are used, an index can be computed to indicate dependency on a scale. 


\section{$143^{6}$ Lisa Callaghan and Ann-Marie Towers}

Six items (out of a possible ten) from this measure were present across all datasets, and so these items were used to indicate dependency in the current analysis. These six items measured: ability to wash face and hands; to use the toilet; to get in and out of bed or chair; to get around indoors; to get dressed and undressed; and to use the bath or shower. Scores for each item could range from o to 3 , and were summed to give a dependency score from o (total independence) to 18 (most dependent). Cronbach's alpha for these six items was o.903, showing very good internal reliability.

Additional information that was available consistently across all three projects was age group, gender and SPH. The SPH question used was that recommended by the World Health Organisation (WHO-Europe 1996), and asks respondents to rate their general health on a five-point scale, with scores ranging from 1 ('very good') to 5 ('very bad').

Analysis. Data were analysed using a variety of techniques, reflecting the different levels of measurement of the variables of interest. For comparisons between participants in different settings, chi-squared $\left(\chi^{2}\right)$ tests were used when the variable was categorical in nature, using Cramer's Vas a measure of strength of association. When the variable was continuous, $t$-tests or analysis of variance were used. Post-hoc comparisons (the Scheffé test) were used where appropriate to compare differences between groups.

To explore relationships between background variables and outcome variables, non-parametric tests of correlation were employed (Spearman's rho). Chi-squared $\left(\chi^{2}\right)$ tests of association were used to explore relationships between the outcome variables and setting.

Ordinal logistic regression was used to assess whether there was an independent effect of setting on feelings of control over daily life, controlling for the effects of background variables as necessary. The statistical analyses were undertaken using the PASW Statistics 18, release version 18.o.o (SPSS Inc., 2009) computer program.

\section{Results}

\section{Participants}

The sample used for the current analysis comprised of all those participants in the samples described above who had the opportunity to answer the question on control over daily life, and who were aged over $6_{5}$. We excluded the very sheltered housing residents from Study 3 on the basis that these housing models were not directly comparable to newer extra care schemes from Study 1. A large number of participants from the ECH sample were not receiving care and support. To make sure the groups from different settings 
were comparable, we restricted the sample to only those people who were receiving care and support. Previous PSSRU research into extra care has indicated that people living in extra care schemes and people living in extra care villages are quite different in terms of their dependency, with village residents being less dependent, and that the experiences of those living in schemes and villages can be quite different (Bäumker et al. 2012; Callaghan, Netten and Darton 2009), and so for the ECH sample, we also excluded those people living in villages $(\mathrm{N}=26)$ (due to the small number, it was not feasible to analyse them as a separate group). This resulted in a total sample of 618 people: 102 people from ECH, 215 people from care homes and 301 people receiving care at home.

The care home sample used in the analysis for this paper was made up of care home residents drawn from two studies (Studies 2 and 3 described above). However, tests indicated that there were no significant differences between these two groups on any of the demographic, health or dependency variables.

The care home sample drawn from the 'Measuring Outcomes of Care Homes' project $(\mathrm{N}=127)$ was a subsample of the larger sample used in the original study $\left(\mathrm{N}=35^{8}\right)$, representing those people who were able to take part in an interview and self-report. Tests indicated that there was no difference in the proportions of men to women between the self-report group and the rest of the sample, in age or in SPH scores, but that the subsample were significantly less dependent than the rest of the sample, with a mean dependency score of 5.68 (standard deviation $(\mathrm{SD})=5.31$ ) compared to $10.71 \quad(\mathrm{SD}=5.78) \quad(t=8.043$, degrees of freedom $(\mathrm{df})=349$, $p<0.001)$. This difference is to be expected given that only the most able care home residents are able to take part in structured interviews.

The majority of people in our final sample as a whole (approximately $70 \%$ ) were aged between 70 and 89 . Twenty-two per cent were over go and the minority remaining were between $6_{5}$ and 69 (exact age was not available for all samples, so is not reported here). Seventy per cent of the sample were female, a proportion that might be expected among the older population (Office for National Statistics 2011 ). Forty-four per cent of participants rated their health as fair, while a further $3^{6}$ per cent rated their health as good or very good. The remainder rated their health as bad or very bad. In terms of dependency, the average score on our measure of help needed with ADLs was $5.88(\mathrm{SD}=4.57$, range $=\mathrm{O}-18)$. Information on marital status was not available for the care home participants, so is not reported here.

\section{Key differences related to setting}

In order to check for covariates of setting that may have an effect on control scores, differences between participants in the four settings were examined. 
T A B L E 3. Characteristics of participants in each setting

\begin{tabular}{|c|c|c|c|c|c|c|c|}
\hline & \multicolumn{2}{|c|}{$\begin{array}{c}\text { Extra care } \\
\text { housing } \\
(\mathrm{N}=102)\end{array}$} & \multicolumn{2}{|c|}{$\begin{array}{l}\text { Care homes } \\
(\mathrm{N}=215)\end{array}$} & \multicolumn{2}{|c|}{$\begin{array}{c}\text { Receiving care } \\
\text { at home } \\
(\mathrm{N}=301)\end{array}$} & \multirow[b]{2}{*}{$p$} \\
\hline & $\mathrm{N}$ & $\%$ & $\mathrm{~N}$ & $\%$ & $\mathrm{~N}$ & $\%$ & \\
\hline \multicolumn{8}{|l|}{ Age group: } \\
\hline $65^{-69}$ & 13 & 12.9 & 9 & $4 \cdot 5$ & 27 & 9.0 & $<0.001$ \\
\hline $70-79$ & 29 & 28.7 & 29 & 14.6 & 95 & 31.6 & \\
\hline $8 \mathrm{o}-89$ & 44 & $43 \cdot 6$ & 84 & 42.2 & 137 & $45 \cdot 5$ & \\
\hline 90 and over & 15 & 14.9 & 77 & 38.7 & 42 & 14.0 & \\
\hline Missing & 1 & & 16 & & o & & \\
\hline \multicolumn{8}{|l|}{ Gender: } \\
\hline Male & 27 & 27.6 & 49 & 23.6 & $9^{6}$ & 31.9 & 0.120 \\
\hline Female & 71 & 72.4 & 159 & $7^{6.4}$ & 205 & 68.1 & \\
\hline Missing & 4 & & 7 & & o & & \\
\hline \multicolumn{8}{|l|}{ Self-perceived health: } \\
\hline Very good & 2 & 2.0 & 60 & 28.0 & 19 & 6.3 & $<0.001$ \\
\hline Good & 21 & 20.8 & 60 & 28.0 & 61 & 20.3 & \\
\hline Fair & 57 & $5^{6.4}$ & 72 & 33.6 & 143 & 47.5 & \\
\hline $\mathrm{Bad}$ & 19 & 18.8 & 16 & $7 \cdot 5$ & 64 & 21.3 & \\
\hline Very bad & 2 & $3 \cdot 5$ & 6 & 2.8 & 14 & $4 \cdot 7$ & \\
\hline Missing & 1 & & 1 & & $\mathrm{o}$ & & \\
\hline \multicolumn{8}{|c|}{ Dependency-ADL score: } \\
\hline Mean & 5.88 & & $5 \cdot 16$ & & $6.4^{\circ}$ & & 0.010 \\
\hline Standard deviation & 3.94 & & 4.65 & & 4.64 & & \\
\hline Range & $0-18$ & & $0-18$ & & $\mathrm{o}-18$ & & \\
\hline Missing & 11 & & 2 & & 5 & & \\
\hline
\end{tabular}

Note: ADL: activities of daily living.

Table 3 shows the characteristics of participants in each setting. There was a significant difference in age according to setting $\left(\chi^{2}=5^{6.5^{17}}, \mathrm{df}=6\right.$, $p<0.001$; Cramer's $V=0.217, p<0.001)$. In extra care schemes, there were fewer people over the age of go than might be expected if there was no relationship. In contrast, in care homes, there were more people than might be expected over the age of 90 , but fewer people than might be expected aged $65^{-69}$ and aged $7 \mathrm{O}^{-}-79$. More people living at home were aged $7 \mathrm{O}^{-}-79$ than might be expected, and fewer of this group were aged over go. Although exact age was not available, we might surmise that care home residents were the oldest on average, which is unsurprising given that the profile of people living in care homes is becoming older and increasingly dependent (Laing and Buisson 2012). There was no significant relationship between gender and setting.

There was a significant relationship between SPH and setting $\left(\chi^{2}=86.877\right.$, $\mathrm{df}=8, p<0.001$; Cramer's $V=0.266, p<0.001)$, with more extra care residents than expected rating their health as 'fair', but fewer rating their 
health as very good. People receiving care at home were also less likely to rate their health as very good, and were more likely to rate their health as bad. In contrast, care home residents were more likely to rate their health as good or very good, and less likely to rate it as bad or very bad.

Turning to dependency, as measured by level of need for help with ADLs, again there was a significant relationship with setting $(F(2,597)=4.627$, $p=0.010$ ). Post-hoc comparison tests (Scheffé) indicated that the only significant difference was that people receiving care at home were more dependent than care home residents $(p=0.010)$; higher scores indicating greater dependency. These results are likely to reflect the fact that our care home sample includes only the less-dependent care home residents; those able to take part in the structured interviews.

\section{Relationships between background variables}

The relationships between these background variables (dependency, SPH, age and gender) were tested. There was a significant relationship between dependency and SPH $(r=0.242, p<0.001)$ with greater dependency related to worse SPH, and between dependency and age $(r=-0.120, p=0.004)$, with older age being associated - surprisingly - with being less dependent. When examined by setting (extra care, care home and home care), the association between age and dependency was only significant for older home care recipients. This relationship is not present in the population from which it was drawn, which had a higher proportion of older people aged over 80 years old (Malley et al. 2012). Perhaps, in the very top age bands, only the most able home care recipients agreed to take part in the research, explaining the weak but significant relationship we have found here. Age was also associated with gender, with women being older on average than men $(r=0.159$, $p<$ O.OO1).

\section{Control over daily life}

Control over daily life was significantly related to dependency $(r=-0.339$, $p<0.001)$ and SPH $(r=-0.245, p<0.001)$, with greater dependency and worse SPH associated with feeling less in control. Older age was associated with feeling more in control $(r=0.117, p=0.004)$ but when this was examined by setting, the relationship only held in ECH. There was no association with gender.

Table 4 shows that feelings of control over daily life varied according to setting $\left(\chi^{2}=35.062, \mathrm{df}=4, p<0.001\right.$; Cramer's $\left.V=0.169, p<0.001\right)$. More extra care scheme residents and more care home residents had 'no needs' (i.e. felt that they had control over their daily lives) than might be expected if 
T A в L E 4. Control over daily life by setting

\begin{tabular}{|c|c|c|c|}
\hline & $\begin{array}{l}\text { Extra care schemes } \\
\qquad(\mathrm{N}=181)\end{array}$ & $\begin{array}{l}\text { Care homes } \\
(\mathrm{N}=215)\end{array}$ & $\begin{array}{l}\text { Receiving care at home } \\
\qquad(\mathrm{N}=301)\end{array}$ \\
\hline \multicolumn{4}{|l|}{ No needs: } \\
\hline Count (\%) & $8_{3}(82.2)$ & $175(81.4)$ & $181(60.1)$ \\
\hline Expected count & 71.9 & 153.0 & 214.2 \\
\hline Adjusted residual & 2.7 & $4 \cdot 1$ & -5.9 \\
\hline \multicolumn{4}{|l|}{ Some needs: } \\
\hline Count $(\%)$ & $13(12.9)$ & $32(14.9)$ & $94\left(3^{1.2}\right)$ \\
\hline Expected count & 22.8 & $4^{8.4}$ & 67.8 \\
\hline Adjusted residual & -2.5 & $-3 \cdot 3$ & $5 \cdot 0$ \\
\hline \multicolumn{4}{|l|}{ High needs: } \\
\hline Count $(\%)$ & $5(5.0)$ & $8(3 \cdot 7)$ & $26(8.6)$ \\
\hline Expected count & 6.4 & 13.6 & 19.0 \\
\hline Adjusted residual & -0.6 & -1.9 & 2.3 \\
\hline
\end{tabular}

there was no association, compared with fewer than expected people receiving care at home. Fewer extra care scheme residents and fewer care home residents, but more people receiving care at home, had some needs than might be expected. More people receiving care at home had high needs than might be expected.

These results are interesting, but the associations presented earlier between some of the background variables and setting indicate that it is important to control for potential confounds (dependency, age and SPH) in order to assess whether setting has an independent effect on feelings of control over daily life. In order to do this, ordinal logistic regression (Hosmer and Lemeshow 2000; Tabachnick and Fidell 2007) was used to assess the unique effect of setting on level of control while background factors (dependency, SPH and age) were controlled. The goal here was specifically to study the association between control and setting, rather than to predict category membership; ordinal regression can be used for either or both (Norusis 2010).

Although ordinal regression has fewer assumptions than multiple linear regression, there are nonetheless a number of assumptions that must be met (Norusis 2010; Strand, Cadwallader and Firth 2011). Initial models failed some of the assumptions, mainly due to extremely high numbers of empty cells produced by combinations of the variables of interest. In order to address this, some categories of the SPH and age variables which contained few responses were collapsed (in the case of SPH, 'good' and 'very good', and 'bad' and 'very bad' were grouped together, while the age groups $65^{-5} 59$ and $70-79$ were also combined). Nonetheless, the final model still contained a large number of cells with low or zero counts, meaning that goodness-of-fit tests must be treated with caution (Norusis 2010; Strand, Cadwallader and 
Firth 2011). The ratio of case to variables was acceptable, even when accounting for missing variables. The Test of Parallel Lines indicated that the assumption of proportional odds was met.

The ordinal regression model contained four explanatory variables: setting (the key variable of interest), age group, SPH and dependency (ADL score). Gender was removed from the model as it was not found to be significant. The outcome variable was control over daily life, with three levels: high needs (no control), some needs (some control but not enough) and no needs (in control of daily life). The model was a significant improvement over the baseline (intercept only) model, $\chi^{2}\left(7,5^{83}\right)=125.161, p<0.001$. It analysed 583 cases and excluded 35 due to missing data on one or more variables. The model explained between 19 per cent (Cox and Snell $R^{2}$ ) and 25 per cent (Nagelkerke $R^{2}$ ) of the variance in feelings of control, and the model fit statistics suggested that the model was a good fit although, as noted above, this should be treated with caution. As the proportion of variance explained is fairly low, the model is likely to be a poor predictor of outcome for any particular individual; but this does not negate the fact that there is a statistically significant difference in the average level of control for people with different levels of SPH and dependency and living in different settings.

Each of the explanatory variables made a unique contribution to the model. Table 5 shows the contribution of the individual variables. As we might expect, as dependency increases, the probability of feeling in control over daily life decreases: the odds of feeling more in control decrease by o.86 for each unit increase in the dependency scale. Similarly, those rating their health as 'very good' or 'good' were 2.96 times more likely, and those rating their health as 'fair' 2.27 times more likely, to feel in control than those rating their health as 'bad' or 'very bad'. It seems that, unsurprisingly, feeling more in control over daily life is associated with being less dependent and rating health more positively.

One level of the age group variable was significantly related to control: participants aged $80-89$ were 0.54 times less likely to feel in control than those over 9o, although there was no effect for people aged $65-79$, suggesting that the relationship between age and feelings of control is not straightforward.

Turning to setting, people living in extra care schemes were 3.68 times more likely to feel in control than those receiving care at home, while people living in care homes were 2.13 times more likely to feel in control than those receiving care at home. The relative values of the coefficients indicate that, when compared to those receiving care at home, those living in extra care schemes are most likely to feel in control, followed by those in care homes, with people receiving care at home least likely to feel in control. 
1442 Lisa Callaghan and Ann-Marie Towers

T А в L Е 5. Ordinal regression analysis of control over daily life as a function of setting and background variables

\begin{tabular}{|c|c|c|c|c|c|c|}
\hline Variable & Parameter & $B$ & SE & OR & $95 \% \mathrm{CI}$ & $p$ \\
\hline \multirow[t]{2}{*}{ Threshold } & High needs & $-3 \cdot 4^{\circ}$ & $0.3^{8}$ & - & -4.15 to -2.65 & $<0.001 * *$ \\
\hline & Some needs & -1.21 & 0.34 & - & -1.88 to -0.53 & $<0.001 * *$ \\
\hline Dependency & $\begin{array}{l}\text { (Continuous } \\
\text { scale) }\end{array}$ & -0.16 & 0.22 & 0.86 & -0.20 to -0.11 & $<0.001 * *$ \\
\hline \multirow{2}{*}{$\begin{array}{l}\text { Self-perceived } \\
\text { health }\left(\text { base }{ }^{1}=\text { very }\right. \\
\text { bad, bad) }\end{array}$} & $\begin{array}{l}\text { Very good, } \\
\text { good }\end{array}$ & 1.08 & 0.27 & 2.96 & 0.55 to 1.62 & $<0.001 * *$ \\
\hline & Fair & 0.82 & 0.24 & 2.28 & 0.35 to 1.30 & $0.001^{* *}$ \\
\hline $\begin{array}{l}\text { Age group } \\
\quad(\text { base }=9 \mathrm{O}+)\end{array}$ & $\begin{array}{l}65-79 \\
80-89\end{array}$ & $\begin{array}{l}-0.37 \\
-0.62\end{array}$ & $\begin{array}{l}0.31 \\
0.29\end{array}$ & $\begin{array}{l}0.69 \\
0.54\end{array}$ & $\begin{array}{l}-0.97 \text { to } 0.22 \\
-1.18 \text { to }-0.06\end{array}$ & $\begin{array}{l}0.219 \\
0.031^{*}\end{array}$ \\
\hline \multirow[t]{2}{*}{$\begin{array}{l}\text { Setting (base }=\text { home } \\
\text { care) }\end{array}$} & $\begin{array}{l}\text { Extra care } \\
\text { housing }\end{array}$ & 1.30 & 0.33 & 3.68 & o.66 to 1.95 & $<0.001 * *$ \\
\hline & Care homes & 0.76 & 0.24 & 2.13 & 0.28 to 1.23 & $0.002 * *$ \\
\hline
\end{tabular}

Notes: SE: standard error. OR: odds ratio. CI: confidence interval. 1. 'Base' refers to the variable parameter against which comparisons are made. For dependency, higher scores equate to being more dependent.

Significance levels: $* p<0.05, * * p<0.01$.

The model described above has a flaw; it only tells us how extra care and care homes compare with home care. It cannot tell us how care homes and extra care compare with each other, and we are interested in the relationship between all three settings. Consequently, the analysis was re-run, using exactly the same model, but changing the 'base category' of the setting variable, to care homes. When care homes were the reference category, the model indicated that people receiving care at home were 0.47 times less likely to feel in control than those living in care homes, but there was no significant effect when comparing the experiences of extra care and care home residents (see Table 6).

Taking these results together, it would seem that there is some evidence that ECH residents in our sample were the most likely to feel more in control of their daily lives. However, the analysis seems to suggest quite strongly that people receiving care at home in our sample were less likely to feel in control than both extra care and care home residents, even after controlling for the effects of confounds such as dependency, age and SPH.

\section{Discussion}

The main objective of this paper was to compare older people's sense of control in different care settings: at home, in ECH and in care homes. Drawing on work developing the ASCOT, we were able to use comparable data from four different research studies to achieve this. Logistic regression 
Older people’s experiences in different care settings 1443

T А в L E 6. Ordinal regression analysis, with 'care homes' as base category

\begin{tabular}{llccccl}
\hline Variable & Parameter & $B$ & SE & OR & \multicolumn{1}{c}{$95 \%$ CI } & \multicolumn{1}{c}{$p$} \\
\hline $\begin{array}{l}\text { Setting } \text { (base }^{1}=\text { care } \\
\text { homes) }\end{array}$ & $\begin{array}{l}\text { Home care } \\
\text { Extra care } \\
\text { housing }\end{array}$ & -0.76 & 0.24 & 0.47 & -1.23 to -0.28 & $0.002^{* *}$ \\
& & & & & & 0.37 \\
& & & & & &
\end{tabular}

Notes: SE: standard error. OR: odds ratio. CI: confidence interval. 1. 'Base' refers to the variable parameter against which comparisons are made.

Significance level: ** $p<0.01$.

analyses showed a consistent pattern of results. Even after controlling for the independent effects of dependency, self-rated health and age group, setting had a significant effect on older people's sense of control. Residents in care homes and ECH reported similar levels of control over daily life but consistently reported feeling more in control than older people living at home and receiving home care.

The results presented here mirror those found by Boyle (2004). They are interesting but perhaps not surprising given recent accounts of the poor quality of domiciliary care in England (EHRC 2011). We know from previous research that older people value having control over the delegation of their care and responsibilities (Bamford and Bruce 2000; Qureshi et al. 1998) and influencing how and when care and support is delivered (Gabriel and Bowling 2004; Qureshi and Henwood 2000; Qureshi et al. 1998). In home care this is sometimes not the case (Aronson 2002; EHRC 2011; Raynes et al. 2001) and is arguably more difficult to achieve in a communitybased model than in a group housing-based model, such as extra care or residential care.

Aspects of ECH frequently reported as important and valued by older people are: having your own front door; the philosophy of ageing in place and maintaining independence; care and support on site; location and transport; design and facilities; social factors; and feeling safe and secure (Baker 2002; Bartholomeou 1999; Croucher, Hicks and Jackson 2006; Croucher, Pleace and Bevan 2003; Oldman 2000). Thus, it seems that people do not have to 'stay put' to feel they have retained their independence and sense of living in their own home but by moving into housing with care they can benefit from the care, support and social aspects associated with living in a more communal setting. Similarly, older people who had recently moved into residential care told researchers that they had more control over their daily lives than they expected, their quality of life had improved, their health needs were better met and they were socialising as much or more than they used to (Darton 2011). 


\section{Lisa Callaghan and Ann-Marie Towers}

Whilst it is important to acknowledge and address the issues with receiving care at home, we also need to recognise the role of financial constraints. The benefits associated with on-site care in care homes and ECH come at a cost. Residential care homes are expensive and generally reserved for the most dependent (Laing and Buisson 2012; Wanless 2006). It would be wholly inappropriate and detrimental to people's control over daily life to move into a care home prematurely, when only a few hours care and support a week is required. However, perhaps the current system has gone too far the other way? We know that the recent trend in service deployment is away from low-level service interventions towards more intensive service packages, with a decline in the number of people receiving home care but an increase in the number of hours of care provided overall, reflecting in part increases in local authority eligibility criteria (Laing and Buisson 2011). Whilst home care should and could go beyond the provision of personal care and help with basic ADLs, for state-funded care this is rarely the case for older people. This is an issue related to resource levels: per capita social care funding is lower for older people than for younger people with equivalent levels of need (Forder 2008) and there is also evidence that PBs for older people are often lower than for younger groups (Slay 2011). Additional funding and resources would be required to help people get out of their houses, engage in social activities or make them feel safe. Theories of environmental fit have long considered the issues associated with changing levels of dependency (Iwarsson 2005; Iwarsson et al. 2007; Lawton 1986). Our needs change as we age and our physical and social environment must also change to accommodate these needs (Commission for Architecture and Built Environment 2009). For example, a large garden that was once a pleasure to maintain becomes a burden and a source of concern. Without appropriate support, home may no longer be considered a place of refuge but rather a place of disempowerment and, in some extreme cases, a place of imprisonment (Baker 2002; Bartholomeou 1999; Boyle 2004; Oldman 200o; Riseborough and Niner 1994).

Extra care housing offers a third way, a compromise between 'staying put' and institutional care. However, people living in extra care - if supported by the local authority-are funded through a number of other sources alongside social care funding: housing benefit; other welfare benefits; and Supporting People funding (Laing and Buisson 2010). This means that the overall cost to the state is likely to be more than that for people receiving care at home in the community, at least in the short term, although it may be that there are savings to be gained in the longer term (Kneale 2011). There is also is evidence that ECH can provide a costeffective alternative to care homes for some older people (Bäumker et al. 2011). 
The level of ECH provision is, however, fairly small. The Elderly Accommodation Counsel (2012) estimates that there were around 55,700 units of extra care accommodation in England in 2011. In comparison, there were 275, Ooo personal care places and 192, 000 nursing home places in care homes in the UK (Laing and Buisson 2012). Although the Labour government attempted to stimulate growth in the market through provision of the Extra Care Housing Initiative Fund $\left(2004^{-10}\right)$, investment in ECH is likely to be reduced given the lack of public funds in the current financial climate, particularly if decision makers are focused on short- rather than longer-term cost savings. In addition, access to ECH schemes is restricted by the eligibility criteria set by the schemes, whether these are as basic as age, links to the local community and housing needs, or shaped by more specific criteria set by local authorities seeking to place individuals in schemes based on additional factors such as health and dependency (Bäumker et al. 2012). Thus, in reality, a large proportion of older people with a need for care and support will remain in their own accommodation in the community.

Given these restrictions, efforts may be best directed at improving services for older people living in their own homes and increasing access to and uptake of services that get people out of their houses, socialising and engaging with their community, and receiving care and support in more flexible ways, thus increasing their sense of control. Perhaps one solution would be for ECH to act as a 'hub', delivering personalised care and support to people in the local community, who can also come to the scheme for communal activities (see e.g. Blood and Pannell 2012). However, it is not clear that this would necessarily overcome the issues associated with scheduled care, which when not available 'on-site' is difficult to provide on demand. In theory, the continued drive towards personalisation of services and giving service users a PB to spend as they wish to meet their needs should result in increased control over how and when care is delivered; however, as noted above, the evidence does not yet indicate that this is the case for all older people receiving care at home (EHRC 2011). Nonetheless, the sample of home care recipients used for the analysis in this paper were receiving conventional home care rather than purchasing this themselves through a $\mathrm{PB}$, and we cannot rule out the possibility that our findings would be different if data were collected from people experiencing the new system.

This paper has drawn from a body of work undertaken during the development of the ASCOT. It is based on secondary analysis and was not the primary purpose for data collection. Limitations to this approach include: compromises over the variables included in the model (e.g. a reduced number of indicators for ADLs); variation in the position of the dependent variable in the interview schedules; and some variation in the wording of the dependent variable as it was developed over time. Regarding the latter, 


\section{$144^{6}$ Lisa Callaghan and Ann-Marie Towers}

however, it should be noted that the only differences in response categories were with the top two levels and we overcame these by collapsing them into a single 'no needs' category. This is in line with current ASCOT scoring for use in care homes and housing with care (see www.pssru.ac.uk/ASCOT).

We should also note that the samples included here are not entirely representative of the populations from which they were drawn. In the care home sample, we only included those able to take part in structured interviews: the more 'independent' residents. In the extra care sample, we only included people receiving care and so compared with the other people living in their schemes they are less able/independent. For home care, our sample is fairly representative. The only difference worth noting is that, compared with the population from which it was drawn, our sample has proportionally less people aged over 8o. We have controlled for differences in dependency in the regression but what we cannot control for is the effect of 'reference category'.

A common problem in quality of life research is understanding the appraisal system used when judging subjective questions such as 'how is your general health' and 'how would you rate your quality of life' (Schwartz and Rapkin 2004). Perhaps the care home residents included in our sample felt more in control than the home care sample because they compared their own situation to that of the frail, less independent residents they lived with? Had we self-report interviews with all residents, we would be able to look at this more closely. However, because the more dependent residents lacked capacity to take part in face-to-face interview, we only have third-party judgements of their control over daily life, which is not directly comparable. The extra care residents reported better control over daily life than home care users, despite requiring more care than the population from which they are drawn. This bodes well for extra care but does not aid interpretation of the findings from home care users.

Finally, the length of time a person receives social care may be an unmeasured contributing factor to people's responses. Policies to keep people out of care homes for as long as possible mean that many have had time to adjust to worsening health and receipt of care by the time they move in. Comparatively, people receiving home care may still be struggling to adapt to their own physical frailty and this might be reflected in their responses to the control over daily life question. Ultimately, without asking people to explain their own individual appraisal process when answering the questions, it is very difficult to resolve these issues (Schwartz and Rapkin 2004). The focus of our analysis was on social care-related control over daily life and our aim was to explore whether this varied according to the care model: care at home, extra care and care homes. The analysis suggests it does. The more able care home residents, those most closely comparable to 
extra care residents, report very similar levels of control over daily life to people living in ECH facilities. The majority feel in control over their daily lives. By comparison, older home care users consistently report lower levels of control. Primary research exploring the issues identified in this paper is urgently required to address our concerns about frail older people living in their own homes and receiving social care. This is a population capable of taking part in surveys and face-to-face interviews. What would make them feel more in control of their daily lives? We have identified several possible explanations for our findings but only by working with service users and their families, providers and commissioners can significant steps be made to improve outcomes through more personalised services and service delivery.

\section{Acknowledgements}

This paper draws on four projects supported by different funders: (1) the Social Well-being project, funded by the Joseph Rowntree Foundation; (2) the Measuring Outcomes of Public Service Users project, funded over three years (2007-o9) by the UK Treasury and led by the Office of National Statistics; (3) the Control and Well-being project, funded by the Department of Health as part of a long-term programme of research; and (4) the Outcomes of Social Care for Adults project, funded by the UK National Institute for Health Research (NIHR) Health Technology Assessment Programme (project reference number o6/96/o1). The analysis and write-up of this paper was funded by the Quality and Outcomes of Person Centred Care Research Unit (QORU). The views and opinions expressed are those of the authors alone and do not necessarily reflect those of the funders. We are very grateful to all those who participated in the research and to those who collected the data. We are also grateful to Professor Ann Netten and Professor Julien Forder for their comments and advice.

\section{References}

Aronson, J. 2002. Elderly people's accounts of home care rationing: missing voices in long-term care policy debates. Ageing E् Society, 22, 4, 399-418.

Baker, T. 2002. An Evaluation of an Extra Care Scheme: Runnymede Court. Hanover Housing Association, Plymouth, UK.

Bamford, C. and Bruce, E. 200o. Defining the outcomes of community care - the perspectives of older people with dementia and their carers. Ageing E्E Society, 2o, 5 , $543-70$.

Barrett, P., Hale, B. and Gauld, R. 201 2. Social inclusion through ageing-in-place with care? Ageing E Society, 32, 3, 361-78.

Bartholomeou, J. 1999. A View of the Future-The Experience of Living in Extra Care. Hanover Housing Group, Staines, UK.

Bäumker, T., Callaghan, L., Darton, R., Holder, J., Netten, A. and Towers, A. 2012. Deciding to move into extra care housing: residents' views. Ageing E् Society, 32, 7 , $1215^{-45}$. Published online 17 October, doi:10.1017/So $144686 \mathrm{X} 11000869$. 


\section{Lisa Callaghan and Ann-Marie Towers}

Bäumker, T., Netten, A., Darton, R. and Callaghan, L. 201 1. Evaluating extra care housing for older people in England: a comparative cost and outcome analysis with residential care. Journal of Service Science and Management, 4, 4, 523-39.

Bernard, M., Bartlam, B., Sim, J. and Biggs, S. 2007. Housing and care for older people: life in an English purpose-built retirement village. Ageing $\mathcal{E} 2$ Society, 27, 4, $555^{-78 .}$

Blood, I. and Pannell, J. 201 2. Building Mutual Support and Social Capital in Retirement Communities. Housing LIN Viewpoint 23, Housing Learning and Information Network, London.

Bowers, H., Clark, A., Crosby, G., Easterbrook, L., Macadam, A., MacDonald, R., Macfarlane, A., Maclean, M., Patel, M., Runnicles, D., Oshinaike, T. and Smith, C. 2009. Older People's Vision for Long-term Care. Joseph Rowntree Foundation, York, UK.

Boyle, G. 2004. Facilitating choice and control for older people in long-term care. Health and Social Care in the Community, 12, 3, 21 2-20.

Caiels, J., Forder, J., Malley, J., Netten, A. and Windle, K. 2010. Measuring the Outcomes of Low-level Services: Final Report. PSSRU Discussion Paper 2699, Personal Social Services Research Unit, Canterbury, UK.

Callaghan, L., Netten, A. and Darton, R. 2009. The Development of Social Wellbeing in New Extra Care Housing Schemes. Joseph Rowntree Foundation, York, UK.

Commission for Architecture and Built Environment 2009. Homes for Our Old Age: Independent Living by Design. Commission for Architecture and Built Environment, London.

Croucher, K., Hicks, L. and Jackson, K. 2006. Housing with Care for Later Life: A Literature Review. Joseph Rowntree Foundation, York, UK.

Croucher, K., Pleace, N. and Bevan, M. 2003. Living at Hartrigg Oaks: Residents' Views of the UK's First Continuing Care Retirement Community. Joseph Rowntree Foundation, York, UK.

Dalley, G. (ed.) 2002. Independence and Autonomy - The Twin Peaks of Ideology. Centre for Policy on Ageing, London.

Darton, R. 201 1. Study of Care Home Residents' and Relatives' Expectations and Experiences. Registered Nursing Home Association, Birmingham, UK.

Darton, R., Bäumker, T., Callaghan, L., Holder, J., Netten, A. and Towers, A. $2011 a$. The characteristics of residents in extra care housing and care homes in England. Health and Social Care in the Community, 2o, 1, 87-96.

Darton, R., Bäumker, T., Callaghan, L. and Netten, A. $2011 b$. Evaluation of the Extra Care Housing Initiative: PSSRU Technical Report. PSSRU Discussion Paper No. 2783/2, Personal Social Services Research Unit, University of Kent, Canterbury, UK.

Darton, R. and Muncer, A. 2005. Alternative housing and care arrangements: the evidence. In Roe, B. and Beech, R. (eds), Intermediate and Continuing Care-Policy and Practice. Blackwell, London, 183-203.

Department for Communities and Local Government 2008. Lifetime Homes, Lifetime Neighbourhoods. A National Strategy for Housing in an Ageing Society. Department for Communities and Local Government, London.

Department of Health 2005. Independence, Wellbeing and Choice: Our Vision for the Future of Social Care for Adults in England. The Stationery Office, London.

Department of Health 2008. Extra Care Housing: What Is It? Housing Learning and Information Network, London.

Department of Health 2010. A Vision for Adult Social Care: Capable Communities and Active Citizens. Department of Health, London. 
Elderly Accommodation Counsel 201 2. Statistics on Specialist Housing Provision for Older People in England. Elderly Accommodation Counsel, London.

Equality and Human Rights Commission (EHRC) 201 1. Close to Home: An Inquiry into Older People and Human Rights in Home Care. EHRC, London.

Forder, J. 2008. The Costs of Addressing Age Discrimination in Social Care. PSSRU Discussion Paper No. 2538, Personal Social Services Research Unit, University of Kent, Canterbury, UK.

Gabriel, Z. and Bowling, A. 2004. Quality of life from the perspectives of older people. Ageing E् Society, 24, 5, 675-91.

Gardner, I. L., Browning, C. and Kendig, H. 2005. Accommodation options in later life: retirement village or community living? Australasian Journal on Ageing, 24, 4, $188-95$.

Glendinning, C., Challis, D., Fernandez, J., Jacobs, S., Jones, K., Knapp, M., Manthorpe, J., Moran, N., Netten, A., Stevens, M. and Wilberforce, M. 2008. Evaluation of the Individual Budgets Pilot Programme: Final Report. Social Policy Research Unit, York, UK.

Hatton, C. and Waters, J. 201 1. The National Personal Budget Survey: Summary of Main Findings. University of Lancaster and In Control, Lancaster, UK.

Hayden, C., Boaz, A. and Taylor, F. 1999. Attitudes and Aspirations of Older People: A Qualitative Study. Research Report No. 102, Corporate Document Services, London.

HM Government 2010. Equity and Excellence: Liberating the NHS. Department of Health, London.

Hosmer, D. and Lemeshow, S. 2000. Applied Logistic Regression. Second edition, John Wiley and Sons, New York.

Iwarsson, S. 2005. A long-term perspective on person-environment fit and ADL dependence among older Swedish adults. The Gerontologist, 45, 3, 327-36.

Iwarsson, S., Wahl, H.-W., Nygren, C., Oswald, F., Sixsmith, A., Sixsmith, J., Széman, Z. and Tomsone, S. 2007. Importance of the home environment for healthy aging: conceptual and methodological background of the European Enable-Age Project. The Gerontologist, 47, 1, 78-84.

Kane, R. L., Bershadsky, B., Kane, R. A., Degenholtz, H. H., Liu, J.J., Giles, K. and Kling, K. C. 2004. Using resident reports of quality of life to distinguish among nursing homes. Gerontologist, 44, 5, 624-32.

Kingston, P., Bernard, M., Biggs, S. and Nettleton, H. 2001. Assessing the health impact of age-specific housing. Health and Social Care in the Community, $\mathbf{9}$, $4,228-34$.

Kneale, D. 2011 . Establishing the Extra in Extra Care: Perspectives from Three Extra Care Housing Providers. International Longevity Centre - UK, London.

Laing, and Buisson, 2010. Extra-care Housing UK Market Report 2010 . Tenth edition, Laing and Buisson, London.

Laing, and Buisson, 201 1. Domiciliary Care UK Market Report 20 I I. Eleventh edition, Laing and Buisson, London.

Laing, and Buisson, 2012. Care of Elderly People UK Market Survey 2OII/I 2. Twenty-fourth edition, Laing and Buisson, London.

Lawton, M.P. 1986. Environment and Ageing. Centre for the Study of Ageing, New York.

Mahoney, F. I. and Barthel, D. W. 1965. Functional evaluation: the Barthel Index. Maryland State Medical Journal, 14, 2, 61-5.

Malley, J., Towers, A.-M., Netten, A., Brazier, J., Forder, J. and Flynn, T. 201 2. An assessment of the construct validity of the ASCOT measure of social care-related quality of life with older people. Health and Quality of Life Outcomes, 10, 21. 


\section{Lisa Callaghan and Ann-Marie Towers}

Netten, A., Beadle-Brown, J., Trukeschitz, B., Towers, A., Welch, E., Forder, J., Smith, J. and Alden, E. 2010. Measuring the Outcomes of Care Homes: Final Report. PSSRU Discussion Paper 2696/2, Personal Social Services Research Unit, University of Kent, Canterbury, UK.

Netten, A., Burge, P., Malley, J., Potoglou, D., Towers, A.-M., Brazier, J., Flynn, T., Forder, J. and Wall, B. $2012 a$. Outcomes of social care for adults: developing a preference-weighted measure. Health Technology Assessment, 16, 16.

Netten, A., Darton, R., Baumker, T. and Callaghan, L. 2011 a. Improving Housing with Care Choices for Older People: An Evaluation of Extra Care Housing. The Housing Learning and Information Network, London.

Netten, A., Jones, K., Knapp, M., Fernandez, J., Challis, D., Glendinning, C., Jacobs, S., Manthorpe, J., Moran, N., Stevens, M. and Wilberforce, M. $2012 b$. Personalisation through individual budgets: does it work and for whom? British Journal of Social Work, 42, 8, $155^{6-75}$.

Netten, A., Trukeschitz, B., Beadle Brown, J., Forder, J., Towers, A. and Welch, E. $2012 c$. Quality of life outcomes for residents and quality ratings of care homes: is there a relationship? Age and Ageing, 41, 4, 51 2-1 7 .

Norusis, M. 2010. PASW Statistics I8.o Advanced Statistical Procedures Companion. Prentice Hall, Englewood Cliffs, New Jersey.

Office for National Statistics 2011. Focus on Older People-Older Peoplés Day 201 I. Office for National Statistics, London.

Office of the Deputy Prime Minister 20o6. A Sure Start to Later Life: Ending Inequalities for Older People. A Social Exclusion Unit Final Report. Office of the Deputy Prime Minister, London.

Oldman, C. 2000. Blurring the Boundaries: A Fresh Look at Housing and Care Provision for Older People. Joseph Rowntree Foundation, Brighton, UK.

Qureshi, H. and Henwood, M. 200o. Older people's definitions of quality services. Briefing paper for the JRF Older People's Steering Group, Joseph Rowntree Foundation, York, UK.

Qureshi, H., Patmore, C., Nicholas, E. and Bamford, C. 1998. Outcomes of Social Care for Older People and Carers. Outcomes in Community Care Practice No. 5, Social Policy Research Unit, University of York, York, UK.

Raynes, N. V. 1998. Involving residents in quality specification. Ageing E Society, 18, 1 , $65^{-78 .}$

Raynes, N., Temple, B., Glenister, C. and Coulthard, L. 2001. Quality at Home for Older People; Involving Service Users in Defining Home Care Specifications. Joseph Rowntree Foundation, York, UK.

Riseborough, M. and Niner, P. 1994. I Didn't Know You Cared! A Survey of Anchor's Housing Tenants. Anchor, Oxford.

Schwartz, C. and Rapkin, B. 2004. Reconsidering the psychometrics of quality of life assessment in light of response shift and appraisal. Health and Quality of Life Outcomes, 2, 1, 16.

Skinner, E. A. 1996. A guide to constructs of control. Journal of Personality and Social Psychology, 71, 3, 549-70.

Slay, J. 2011. Budgets and Beyond: Interim Report. A Review of the Literature on Personalisation and a Framework for Understanding Co-production in the 'Budgets and Beyond' Project. New Economics Foundation, London.

Strand, S., Cadwallader, S. and Firth, D. 2011 . Using Statistical Regression Methods in Educational Research: Module 5-Ordinal Regression. Available online at http://www. restore.ac.uk/srme/www/fac/soc/wie/research-new/srme/index.html [Accessed 9 November 2011 ]. 
Tabachnick, B. G. and Fidell, L. S. 2007. Using Multivariate Statistics. Fifth edition, Harper Collins, New York.

Taylor, T., Killaspy, H., Wright, C., Turton, P., White, S., Kallert, T., Schuster, M., Cervilla, J., Brangier, P., Raboch, J., Kalisova, L., Onchev, G., Dimitrov, H., Mezzina R., Wolf, K., Wiersma, D., Visser, E., Kiejna, A., Piotrowski, P., Ploumpidis D., Gonidakis, F., Caldas-de-Almeida, J., Cardoso, G. and King, M. 2009. A Systematic review of the international published literature relating to quality of institutional care for people with longer term mental health problems. BMC Psychiatry, 9, 55, 1-30.

Tester, S., Hubbard, G., Downs, M., MacDonald, C. and Murphy, J. 2004. What does quality of life mean for frail residents? Nursing and Residential Care, 6, 2, 89-92.

Towers, A. 2006. Control, Wellbeing and the Meaning of Home in Care Homes and Extra Care Housing. PSSRU Discussion Paper No. 2342, Personal Social Services Research Unit, University of Kent, Canterbury, UK.

Train, G. H., Nurock, S. A., Manela, M., Kitchen, G. and Livingston, G. A. 2005. A qualitative study of the experiences of long-term care for residents with dementia, their relatives and staff. Aging and Mental Health, 9, 2, 1 19-28.

Wanless, D. 2006. Securing Good Care for Older People: Taking a Long-term View. Kings Fund, London.

WHO-Europe 1996. Health Interview Surveys: Towards International Harmonisation. WHO Regional Publications, European Series No. $5^{8}$, World Health OrganisationEurope, Copenhagen.

Windle, K., Wagland, R., Forder, J., D'Amico, F., Janssen, D. and Wistow, G. 2009. National Evaluation of Partnerships for Older People Projects: Final Report. Personal Social Services Research Unit, University of Kent, Canterbury, UK.

Accepted 28 February 20I3; first published online I6 May 2013

Address for correspondence:

Ann-Marie Towers, Personal Social Services Research Unit (PSSRU), University of Kent, Canterbury CT2 7 NF, UK.

E-mail: A.Towers@kent.ac.uk 